\title{
RESISTANSI PENGARANG MELALUI KONSTRUKSI PEREMPUAN TIMUR DALAM "KARTINI" KARYA PUTU WIJAYA
}

\section{Apri Damai Sagita Krissandi', Anggitya Alfiansari' ${ }^{2}$, Kelik Agung Cahya Setiawan ${ }^{3}$ apridamai@gmail.com ${ }^{1}$, anggityaalfian@gmail.com², keliksky49@gmail.com ${ }^{3}$}

\author{
Program Studi PGSD Universitas Sanata Dharma Yogyakarta ${ }^{1}$, \\ Program Studi Pendidikan Bahasa dan Sastra Indonesia Universitas Negeri Yogyakarta ${ }^{2,3}$
}

\begin{abstract}
Abstrak
Penelitian ini bertujuan untuk menyelami konstruksi diri perempuan Timur serta untuk mengetahui posisi pengarang dalam wacana kolonialisme. Citra diri perempuan Timur masih menjadi topik yang layak diteliti melalui kehadiran karya-karya sastra. Terlebih jika berhubungan dengan perpanjangan tangan akan kolonialisme. Penelitian ini menggunakan pendekatan kualitatif deskriptif dengan sudut pandang feminisme pascakolonial untuk mengungkap konsep diri perempuan. Penelitian ini menemukan adanya konstruksi perempuan ideal yang merdeka secara pikiran tanpa perlu menginduk pada konstruksi tradisional yang menggunakan aksesori tertentu untuk memperempuankan perempuan. Posisi pengarang sendiri merupakan wakil dari si terjajah yang menyuarakan resistansinya dengan cara ambivalensi.
\end{abstract}

Kata kunci: kartini, kolonialisme, konstruksi perempuan, pengarang, resistansi.

\section{Abstract}

This study aims to explore the construction of Eastern women themselves and to find out the position of the author in the discourse of colonialism. Eastern women's self-image is still a topic worthy of research through the presence of literary works. Especially if it is related to the extension of colonialism. This study uses a descriptive qualitative approach with the perspective of postcolonial feminism to uncover women's self-concept. This study found the existence of the construction of ideal women who are free in mind without needing to be in the traditional construction that uses certain accessories to feminize women. The position of the author himself is representative of the colonized who voices his resistance by means of ambivalence.

Keywords: author, colonialism, construction of women, kartini, resistance.

\section{PENDAHULUAN}

Karya sastra Indonesia, baik dari zaman perjajahan maupun era modern ini, merupakan wujud sastra yang terindikasi memiliki dampak-dampak kolonialisme, atau merupakan wujud pascakolonial. Berbicara tentang pascakolonial tidak terlepas dari pengertian kolonialisme maupun imperialisme. Terlebih Indonesia pernah dan/atau masih terbelenggu oleh kedua peristilahan tersebut. Adapun kolonialisme terkait dengan penjajahan secara fisik atau perilaku. Sedangkan imperialisme merupakan penjajahan secara ideologi. Dengan demikian, dapat dilihat secara harfiah bahwa pascakolonial merupakan penjajahan yang pernah berlangsung, sedang berlangsung, maupun setelah berlangsungnya penjajahan tersebut. Said menyebutkan bahwa kekuatan kolonial Barat menghadirkan wilayah atau "dunia yang lain" yang disebut dengan Timur (Susanto, 2012:
255). Bahwa Timur sebagai dramawan sedangkan kaum orientalis sebagai sutradara (Said, 2010:xi). Bahwa orientalisme merupakan suatu cara untuk memahami dunia Timur yang didasarkan pada keeksotikannya di mata orang Eropa (Said, 2010:2).

Warisan peradaban kolonial tersebut salah satunya adalah terlegitimasinya R.A.Kartini sebagai tokoh pejuang hakhak wanita atau yang lebih akrab disebut dengan emansipasi. Berangkat dari warisan tersebut, muncullah beberapa tanggapan dalam karya sastra, baik yang menerima subjek penjajah, resistansi terhadap subjek penjajah, dan ada pula yang ambivalensi dalam berlaku-sikap terhadap subjek penjajah. Salah satu karya sastra modern yang merupakan bentuk respon terhadap keadaan tersebut adalah cerita pendek berjudul "Kartini" yang ditulis oleh Putu Wijaya. Tokoh Kartini dalam cerpen tersebut memberi pelukisan baru tentang sosok Kartini yang sangat 
berlawanan dengan apa yang telah menjadi dogma di masyarakat selama ini. Putu Wijaya telah merombak R.A. Kartiniyang "disembah" masyarakat Indonesiamelalui pengisahan tokoh Kartini kontemporer yang kebarat-baratan.

Tujuan penelitian ini adalah untuk mengetahui citra diri konsep perempuan Timur melalui cerpen "Kartini”" serta untuk mengetahui posisi pengarang dalam wacana kolonial. Putu Wijaya, sang pengarang, yang sekaligus juga bagian dari si terjajah tidak dapat dipungkiri secara psikososial seperti yang disebutkan oleh Bhabha tentang gejolak resistansi si terjajah terhadap sang penjajah. Eksplorasi tersebut tepatnya mempertanyakan kembali pada si terjajah akan konstruksi perempuan yang selama ini telah menjadi dogma di masyarakat. Sedangkan manfaat penelitian ini adalah sebagai wujud rekonstruksi akan pemaknaan terhadap konsep perempuan yang selama ini telah kabur karena wacana sang penjajah yang meleburkan diri dengan keadaan si penjajah, baik secara kebudayaan maupun ideologi.

Teori ini menggunakan gagasan feminisme pascakolonial. Perempuan yang dekat dengan konteks feminisme, dalam era postmodern tidak lagi menitikberatkan pada bagaimana perempuan bisa tertindas oleh konstruksi budaya patriarki. Akan tetapi, lebih mempertanyakan bagaimana kita mengonstruksi konsep perempuan. Ritzer dan Goodman menjelaskan bahwa postmodernisme tidak menawarkan jawaban atas pertanyaan fundamental keilmuan feminis, yaitu "Dan bagaimana dengan para perempuan?" Postmodernisme justru meresponsnya dengan balik bertanya, "Bagaimana Anda mengonstruksi kategori atau konsep 'perempuan'?" (Ritzer dan Goodman, 2010:520).

\section{METODE PENELITIAN}

Penelitian ini merupakan penelitian secara kualitatif dengan objek material cerita pendek karya Putu Wijaya yang berjudul "Kartini". Sementara objek formal dalam penelitian ini adalah konstruksi perempuan dan posisi pengarang dalam wacana pascakolonial yang terilustrasi dalam "Kartini". Data yang dikumpulkan dalam penelitian ini adalah segala hal yang berhubungan dengan topik penelitian, antara lain data teks maupun konteks tentang Kartini sebagai perwakilan ikon perempuan ideal di Indonesia.

Cara penyelesaian masalah dalam penelitian ini adalah pendasaran terhadap teori yang digunakan, yakni feminisme pascakolonial. Pengungkapan akan tekstual yang dihadirkan pengarang secara dekonstruktif sangat mendukung sebagai bentuk eksplorasi dalam penelitian ini.

\section{HASIL DAN PEMBAHASAN}

\section{Konstruksi Perempuan Timur}

"Kartini", sesuai dengan judul, pengisahan cerita terkait dengan tokoh emansipasi Indonesia, Ibu Kita Kartini. Secara dekonstruktif, Putu Wijaya telah melakukan perombakan ikon R.A. Kartini menjadi sosok yang kontemporer dan cenderung dipandang negatif oleh orangorang Indonesia-yang terlanjur menggagahkannya sebagai seorang tokoh penting. Tokoh Kartini dalam cerpen "Kartini" oleh Putu Wijaya digambarkan dengan perawakan dan penampilan ala Barat serta pemikiran ala Barat pula. "Kostum" tradisi Jawa pada Kartini yang selama ini melekat dalam dirinya, oleh Putu Wijaya diubah menjadi sosok Kartini yang lebih modern. Kartini pada awalnya memang dikisahkan mengenakan "kostum" kebesarannya, selanjutnya dikisahkan Kartini berganti pakaian dan aksesoris yang tidak lagi tradisional. Cara berpikir Kartini pun, oleh Putu Wijaya dipertahan dengan gaya Barat yang penuh kebebasan dalam menentukan pilihanpilihan.

Berbicara tentang kebebasan dalam menentukan pilihan yang menjadi main 
concept atas pemikiran Kartini yang terpengaruh Barat, mengingatkan akan penulisan ulang Declaration of Independence yang oleh penandatangan didapati bunyi sebagai berikut.

"Kita berpegang teguh pada keyakinan ini sepenuhnya: bahwa seluruh laki-laki dan perempuan ['dan perempuan' adalah tambahan] diciptakan setara; bahwa hakhak tersebut antara lain hak hidup, kebebasan, dan hak untuk mencapai kebahagiaan; bahwa untuk menjamin hakhak ini dibentuk pemerintahan [' $\mathrm{di}$ kalangan laki-laki' dihapuskan], yang mendapatkan kekuasaannya atas sepersetujuan yang diperintah" (Ritzer; Goodman, 2010:499).

Hal tersebut merupakan bentuk protes atau sebut saja pemberontakan kaum perempuan yang tergolong dalam jenis feminisme liberal. Feminisme liberal hadir dalam diri Kartini, baik tokoh Kartini dalam "Kartini" maupun tokoh Kartini sebagai pahlawan emansipasi Indonesia, keduanya tidak bisa terlepas dari cengkraman pascakolonial.

Feminisme liberal berargumen bahwa perempuan dapat mengklaim kesetaraan dengan laki-laki berdasarkan kemampuan hakiki manusia untuk menjadi agen moral yang menggunakan akalnya, yakni bahwa ketimpangan gender adalah akibat dari pola pembagian kerja yang seksis dan patriarkal dan bahwa kesetaraan gender dapat dihasilkan dengan mentransformasikan pembagian kerja melalui pemolaan ulang institusi-institusi kunci hukum, kerja, keluarga, pendidikan, dan media (Ritzer; Goodman, 2010:498).

Feminisme liberal menekankan pada kuasa rasionalitas perempuan, yakni kebebasan dan persamaan berakar pada rasionalitas, atau dengan kalimat lain bahwa perempuan adalah makhluk rasional. Perempuan harus dididik bersaing merebut kesempatan maskulinitas. Di luar negeri pada abad ke-18 marak dengan tututan pendidikan yang sama. Sementara baru ketika Kartini muda mulai tersuarakan kesetaraan yang dicatat oleh sejarah. Tentunya, sejarah bergantung pada siapa yang memiliki kuasa.

Berbicara sedikit tentang sejarah, kehidupan di sekitar Kartini memang terkuasai oleh praktik-praktik patriarkat, yakni sistem sosial yang memberikan posisi dominan bagi laki-laki sebagai sebuah kelompok untuk mengendalikan perempuan. Laki-laki berposisi sebagai superior, sedangkan perempuan sebagai inferior. Itu mengapa Kartini pada akhirnya memberanikan diri untuk mengusung emansipasi sebagai tanda kebebasan pikir kaum perempuan. Dalam kasus ini yang dititikberatkan adalah perihal pendidikan. Feminisme liberal melihat perubahan dengan optimis melalui pembukaan lapangan pekerjaan, kesempatan pendidikan, hingga posisi politik formal bagi perempuan (Walby, 1990:32).

Disebutkan oleh Lewis dan Mitts (2003:2) dalam jurnal Susanto bahwa hubungan antara pascakolonial dan feminis dapat menjadi suatu sintesis, yakni persatuan antara keduanya untuk memasuki berbagai isu tentang gender. Atau dengan kata lain, resituasi antara feminis dan pascakolonial menghasilkan feminis. Pascakolonialisme masih menekankan pada arus utama teori pascakolonialisme.

Dalam feminisme pascakolonial atau dapat pula disebut dengan feminisme Dunia Ketiga, feminis ini lahir sebagai wacana tanding feminis yang dicanangkan oleh Barat sebagai produt kapitalisme dan/atau kolonialisme dengan dalih membentuk konstruksi perempuan Timur sesuai yang dikehendaki oleh mereka. Sehingga, dapat disebut bahwa gerakan feminis yang digalakkan oleh R.A.Kartini juga bagian dari feminisme sebagai agen kolonialisasi.

Kartini telah disalahartikan oleh kebanyakan masyarakat Indonesia dengan perayaan mereka yang tidak masuk akal. Dalam kasus tersebut Putu Wijaya hadir dalam "Kartini"-nya untuk menegaskan 
bahwa Kartini adalah sewujud konsep, bukan sekadar seremoni. Konstruksi citra perempuan Timur yang terwakili melalui tokoh Kartini pun ia hadirkan secara dekonstruktif, yakni dengan perawakan ala Barat yang ironisnya lebih berterima di masyarakat.

Saya berpaling. Seorang wanita cantik berdiri menyemburkan parfum yang segar. Ia memakai T-shirt ketat yang terlalu pendek sehingga perutnya tak tertutup. Blue jean yang melilit pinggangnya begitu rendah sehingga pusarnya kelihatan. Terus terang, meskipun masih pagi, ia sudah terasa mengganggu iman. Ia tersenyum, bibir dan matanya genit. Tapi, itu mungkin hanya perasaan saya yang konyol. Karena ia tampak hendak duduk, saya buru-buru mencegah (Wijaya, 2010:47).

Disebut dekonstruktif karena perempuan dalam "Kartini" sebagai konstruksi pengarang terhadap idealnya perempuan Timur adalah perempuan yang merdeka dalam pikiran dan perbuatan, serta mampu menyesuaikan diri dengan lingkungan. Perempuan tidak melulu tentang yang berkebaya, bergincu, dan bersanggul. Perempuan disebut perempuan adalah jika dia bisa berlaku selayaknya perempuan yang mampu menyesuaikan diri sesuai tempat dan kebutuhan. Perempuan tetaplah perempuan meski tanpa kebaya, gincu, dan sanggul di kepala. Dengan kata lain, perempuan tetaplah seorang perempuan sekalipun tanpa aksesori-aksesori yang oleh masyarakat terlanjur dipatenkan menjadi barang-barang yang hanya boleh dikenakan perempuan.

"Emang kenapa? Ibu kan tidak berubah karena pakaian Ibu diganti. Ibu tetap Ibu walaupun pakai pakaian seperti ini. Ya, kan? Habis, Ibu juga senang karena praktis dan kelihatan aktual. Masak mentangmentang Ibu sudah tua mesti ngelomprot dan pakai pakaian jarik dan kebaya terus? Gerah, kan. O... kenapa, nggak setuju kelihatannya?" (Wijaya, 2010:48).

Kembali pada pertanyaan bagaimana kita mengonstruksi perempuan seperti yang digaungkan oleh feminisme pascakolonial dan bukannya berkutat pada pertanyaan-pertanyaan perihal kesetaraan, secara eksplisit yang diterangkan melalui dialog antartokoh, Putu Wijaya memberi alternatif akan citra diri perempuan Timur yang cerdas secara intelektual tanpa perlu membatasi tubuhnya dengan aksesoris tertentu sehingga menunjukkan eksistensinya sebagai perempuan. Perempuan dalam kaca mata pengarang adalah perempuan yang tahu tempat dan situasi, mampu mengendalikan diri, dan bahkan merdeka secara tubuh dan pikirannya.

\section{Putu Wijaya Wakil Siapa}

Putu Wijaya yang "menakalkan” R.A. Kartini dengan melakukan pemimikrian seorang Timur (yang ditokohkan oleh masyarakat Timur) menjadi seseorang yang kebarat-baratan secara fisik dan akal, sesungguhnya merupakan wujud resistansinya atas pengikonan R.A. Kartini yang tidak lain adalah perpanjangan tangan dari Barat. Disebutkan di atas tentang feminisme liberal yang menjadi titi tolak Kartini dalam melakukan emansipasinya. Terlebih ia hidup sebagai putri bangsawan yang memudahkan pelegitimasiannya sebagai seorang tokoh emansipan. Bahwasanya berbicara tentang kekuasaan, terlebih kekuasaan Jawa, tidak dapat ditanggalkan dari hubungannya dengan sang penjajah. Ketundukan Jawa kepada donimasi politik, ekonomi, dan kebudayaan Barat, telah menggerakkan sebuah proses dekristalisasi yang tak bisa dipulihkan lagi sehingga dapat disebutkan bahwa budaya politik Jawa sekarang ini adalah suatu kompleks unsur-unsur Barat dan tradisional yang heterogen (Anderson, 1990:43). Kartini juga berkawan baik dengan Belanda yang terang saja mempengaruhi pola pikirnya. Itulah mengapa, Kartini disinyalir sebagai panjang tangan sang penjajah yang telah diikonkan oleh masyarakat.

Dalam feminisme pascakolonial, perempuan memiliki penindasan secara 
ganda, yakni karena adanya patriarki dan karena adanya kolonialisme. "Kartini" yang lahir sebagai respon akan adanya kolonialisme dapat dikategorikan dalam dua hal tersebut, yakni sebagai korban patriartki serta merupakan perpanjangan tangan dari kolonialisme.

Untuk sampai pada pembacaan tersebut, dibutuhkan pembalikan strategi serta aktivitas pembacaan teks yang sama sekali baru (Ratna, 2015:136). Culler (1982:85) mengatakan bahwa dalam mendekonstruksi wacana pada intinya adalah merusak oposisi-oposisi hierarkis tempat wacana tersebut bersandar. Resistansi Putu Wijaya tersebut terbilang dilakukan secara dekonstruktif karena ia "menghancurkan" lalu kemudian membangun kembali citra Kartini sesuai dengan kehendak berkisahnya, yang bisa saja memicu kemarahan kaum pembela R.A. Kartini yang telah terhegemoni (yakni masyarakat Indonesia). Padahal secara implisit, Putu Wijaya justru bermaksud meluruskan sejarah dengan cara memunculkan tokoh Kartini yang ia "nakalkan" tersebut.

Menilik kesejarahan Kartini yang telah dipelajari bahkan ditanamkan secara turuntemurun oleh masyarakat Indonesia merupakan bagian dari konteks yang melahirkan karya "Kartini". Keprihatinan pengarang akan fenomena perayaan Kartini yang dilakukan oleh masyarakat menumbuhkan kecemasan berlebih. Terlebih kesejarahan Kartini yang dilegitimasi oleh pemerintahan pada masa itu dengan menobatkannya menjadi pahlawan nasional, yakni SK Presiden RI nomor 108, 2/5/1964 serta ditetapkan pula hari kelahiran beliau sebagai hari emansipasi (jurnal Sudrajat). Kartini hidup di lingkungan bangsawan serta bersinggungan sangat baik dengan kawankawan Belandanya. Kartini yang berpikiran maju kala itu tidak terlepas dari pemikiran Eropa (Barat). Hal ini pula yang ditampakkan oleh Putu Wijaya dalam "Kartini". Perawakan yang kebarat-baratan merupakan simbol tersendiri akan makna implisit yang pengarang hadirkan.

Derrida dalam dekonstruksinya menyebutkan konsep struktural dalam mereduksi dan menafsirkan yang ia sebut sebagai "peristiwa" (Rusbiantoro, 2001:21). Menggunakan konsep pikir yang dekonstruktif, Putu Wijaya bukannya menolak perjuangan Kartini, ia justru ingin meluruskan konsep Kartini agar dapat berterima di masyarakat secara benar dan tidak salah kaprah. Hal pertama yang ingin diperjuangkan Putu Wijaya seperti yang terpapar di atas adalah pelurusan konsep Kartini atau konsep perempuan ideal khas Timur yang tidak terhenti pada penampilan.

"Apa kamu kira hanya dengan memakai pakaian itu aku bisa menjadi perempuan yang ideal? Itu penafsiran Kartini yang terlalu maskulin! Ibu Kartini itu sebuah konsep perjuangan kebebasan dan kesetaraan perempuan, bukan kostum. Laki-laki selalu cenderung untuk menyesatkan supaya kita perempuan lupa pada cita-citanya sehingga peringatan Kartini lebih menjadi seremonial ketimbang pewarisan konsepnya yang mengajak perempuan Indonesia untuk membebaskan dirinya dari segala ikatan. Membebaskan dari dominasi bapak-bapak yang mata keranjang. Kamu mau perempuan kembali menjadi makhluk dapur, sumur dan tempat tidur? Itu kuno, Pak! Kuno sekali! Terlalu ketinggalan zaman!" (Wijaya, 2010:52).

Hal kedua yang ingin diperjuangkan Putu Wijaya adalah pelurusan pemahaman masyarakat Indonesia yang terlanjur terhegemoni dengan mengagungkan R.A.Kartini sebagai pelopor emansipasi. Putu Wijaya hadir dengan membuat tokoh Kartini dalam cerita pendeknya yang digambarkan tidak seperti citra perempuan Timur. Kartini dalam cerpen ini sangat binal secara perilaku dan penampilan.

Apalagi ketika berpaling di pintu, ibu tampak sedang mengeluarkan rokok dari tasnya. Seorang kuli menolongnya dengan geretan. Ibu masih sempat menawarkan 
kepada saya dari jauh, tentu saja segera saya menolak. Saya tidak suka orang merokok di tempat-tempat umum. Apalagi perempuan. Bukan karena saya menganggap merokok itu pekerjaan lakilaki, melainkan karena termakan kampanye jantung sehat. Saya heran mengapa orang setuju saja merayakan upacara bunuh diri itu sambil memperkaya para pemilik pabrik rokok (Wijaya, 2010:49-50).

Meskipun pengarang membentuk tokoh Kartini dalam cerpennya dengan feminis liberal-yang merupakan gerakan Barat dan sengaja disebar luas agar pula menjadi gerakan kaum Timur-bahkan lebih liberal daripada tokoh Kartini dalam sejarah, bukan berarti Putu Wijaya adalah wakil dari sang penjajah yang turut menyuarakan ideologi mereka. Seperti ungkapan Bhabha tentang psikologi kolektif atau psikologi sosial yang mengarah pada keadaan jiwa si terjajah yang selalu ingin melakukan resistansi, baik secara sadar maupun tidak sadar, Putu Wijaya pun demikian.

Pelukisan yang ambivalen dipaparkan Putu Wijaya dalam cerpennya. Bhabha menyebutkan tentang ruang ketiga atau hibriditas atau ruang liminal yang menjadi ruang bagi si terjajah untuk menyuarakan resistansinya secara mimikri. Seperti ungkapan Bhabha yang terdapat dalam Setyaningsih yakni sebagai berikut.

Hibriditas mengganggu kebutuhan mimetik atau narasistik dari kekuasaan kolonial, tetapi mengimplikasikan kembali dengan mengidentifikasikannya dalam strategi subversi yang mengubah pandangan dari yang terdiskriminasi kembali kepada mata kuasa sebab hibrid terjajah merupakan artikulasi dari ruang ambivalen di mana ritus kekuasaan dijalankan pada situs hasrat, menjadikan objeknya terdisiplinkan sekaligus melipatgandakan diri (Setyaningsih, 2015:15).

Dengan kata lain, Putu Wijaya mencitrakan perempuan yang ia serupakan dengan perempuan Barat sehingga ia mendapat stigma yang negatif atas penggambarannya oleh masyarakat Timur yang terlanjur terhegemoni oleh legitimasi R.A.Kartini. Sementara itu, di sisi lain Putu Wijaya justru bermaksud mendekonstruksi pencitraan tersebut untuk membuktikan bahwa R.A.Kartini merupakan produk pascakolonial yang terlanjur kita tokohkan atas pemikiran mengenai kebebasan atau kesetaraan gender bagi perempuan.

\section{SIMPULAN}

Penelitian ini terdiri dari dua simpulan, yaitu yang pertama mengenai konstruksi citra diri perempuan Timur yang terilustrasikan melalui tokoh Kartini dalam cerita pendek "Kartini" karya Putu Wijaya. Perempuan Timur ialah perempuan yang (seyogyanya) cerdas secara intelektual tanpa perlu membatasi tubuhnya dengan aksesoris tertentu sehingga menunjukkan eksistensinya sebagai perempuan. Perempuan (seyogyanya) tahu tempat dan situasi, mampu mengendalikan diri, dan bahkan merdeka secara tubuh dan pikirannya.

Simpulan kedua dari penelitian ini bahwa Putu Wijaya merupakan wakil si terjajah yang melakukan resistansinya dengan cara ambivalen. Ia memanfaatkan penampilan serta perilaku yang penuh kebebasan dari bangsa berideologi liberal untuk menggambarkan citra diri perempuan Timur. Namun, justru melalui hal itu, Putu Wijaya berusaha merombak kenyataan akan sejarah yang terpelintir sebab legitimasi penokohan R.A.Kartini yang dilakukan penguasa pada waktu itu. Bermaksud membuka pikiran para pembaca agar memahami perjuangan Kartini dengan lurus tanpa salah paham, baik secara konsep pemikiran maupun secara penobatannya sebagai seorang tokoh emansipasi wanita di Indonesia. 


\section{DAFTAR PUSTAKA}

Anderson, Bennedict. 1990. Kuasa-Kata: Jelajah Budaya-budaya Politik di Indonesia (Dialihbahasakan Oleh Revianto Budi Santosa). Yogyakarta: Mata Bangsa.

Culler, Jonathan.1983. On Decunstruction: Theory and Criticism After Structuralism. London: Cornell University.

Ratna, Nyoman Kutha. 2015. Estetika: Sastra dan Budaya. Yogyakarta: Pustaka Pelajar.

Ritzer, George dan Goodman, Douglas J. 2010. Teori Sosiologi: Dari Teori Sosiologi Klasik Sampai Perkembangan Mutakhir Teori Sosiologi Postmodern (Dialihbahasakan Oleh Nurhadi). Yogyakarta: Kreasi Wacana.

Rusbiantoro, Dadang. 2001. Bahasa Dekonstruksi Ala Foucault dan Derrida. Yogyakarta: Tiara Wacana Yogya.

Said, Edward W.. 2016. Orientalisme: Menggugat Hegemoni Barat dan Mendudukkan Timur Sebagai Subjek. Yogyakarta: Pustaka Pelajar.

Setyaningsih, Magdhalena Lilis. 2016. Cerita Rakyat Rawa Pening: Kajian Pascakolonial. Surakarta: Universitas Sebelas Maret.

Sudrajat. "Kartini: Perjuangan dan Pemikirannya". Yogyakarta: UNY.

Susanto, Dwi. 2008. "Relasi Sang Ego dan Sang Liyan Tjerita Njai Dasima Soewatoe Koeban Dari Pada Pemboedjoek: Kajian Feminis Pascakolonial". 2012. Pengantar Teori Sastra. Jakarta: Buku Seru.

Walby, Sylvia. 1990. Teorisasi Patriarki (Dialihbahasakan oleh Mustika K. Prasela). Yogyakarta: Jalasutra.

Wijaya, Putu. 2010. Klop. Yogyakarta: Bentang. 